\title{
Uptake of gaseous formaldehyde by soil surfaces: a combination of adsorption/desorption equilibrium and chemical reactions
}

\author{
Guo Li ${ }^{1,2}$, Hang Su${ }^{1}$, Xin Li $^{3}$, Uwe Kuhn ${ }^{1}$, Hannah Meusel ${ }^{1}$, Thorsten Hoffmann ${ }^{4}$, Markus Ammann ${ }^{5}$, Ulrich Pöschl ${ }^{1}$, \\ Min Shao ${ }^{2}$, and Yafang Cheng ${ }^{1}$ \\ ${ }^{1}$ Multiphase Chemistry Department, Max Planck Institute for Chemistry, Mainz, Germany \\ ${ }^{2}$ College of Environmental Sciences and Engineering, Peking University, Beijing, China \\ ${ }^{3}$ Institute for Energy and Climate Research, IEK-8, Research Center Jülich, Jülich, Germany \\ ${ }^{4}$ Institute of Inorganic Chemistry and Analytical Chemistry, Johannes Gutenberg University Mainz, Mainz, Germany \\ ${ }^{5}$ Laboratory of Radiochemistry and Environmental Chemistry, Paul Scherrer Institute, 5232 Villigen, Switzerland \\ Correspondence to: Yafang Cheng (yafang.cheng@mpic.de) and Min Shao (mshao@pku.edu.cn)
}

Received: 30 March 2016 - Published in Atmos. Chem. Phys. Discuss.: 18 April 2016

Revised: 14 July 2016 - Accepted: 28 July 2016 - Published: 15 August 2016

\begin{abstract}
Gaseous formaldehyde (HCHO) is an important precursor of $\mathrm{OH}$ radicals and a key intermediate molecule in the oxidation of atmospheric volatile organic compounds (VOCs). Budget analyses reveal large discrepancies between modeled and observed HCHO concentrations in the atmosphere. Here, we investigate the interactions of gaseous $\mathrm{HCHO}$ with soil surfaces through coated-wall flow tube experiments applying atmospherically relevant $\mathrm{HCHO}$ concentrations of $\sim 10$ to $40 \mathrm{ppbv}$. For the determination of uptake coefficients $(\gamma)$, we provide a Matlab code to account for the diffusion correction under laminar flow conditions. Under dry conditions (relative humidity $=0 \%$ ), an initial $\gamma$ of $(1.1 \pm 0.05) \times 10^{-4}$ is determined, which gradually drops to $(5.5 \pm 0.4) \times 10^{-5}$ after $8 \mathrm{~h}$ experiments. Experiments under wet conditions show a smaller $\gamma$ that drops faster over time until reaching a plateau. The drop of $\gamma$ with increasing relative humidity as well as the drop over time can be explained by the adsorption theory in which high surface coverage leads to a reduced uptake rate. The fact that $\gamma$ stabilizes at a non-zero plateau suggests the involvement of irreversible chemical reactions. Further back-flushing experiments show that two-thirds of the adsorbed HCHO can be re-emitted into the gas phase while the residual is retained by the soil. This partial reversibility confirms that $\mathrm{HCHO}$ uptake by soil is a complex process involving both adsorption/desorption and chemical reactions which must be considered in trace gas exchange (emission or deposition) at the atmosphere-soil interface. Our results suggest that soil and soil-derived airborne
\end{abstract}

particles can either act as a source or a sink for $\mathrm{HCHO}$, depending on ambient conditions and $\mathrm{HCHO}$ concentrations.

\section{Introduction}

Atmospheric $\mathrm{HCHO}$ represents one of the most abundant carbonyls in the atmosphere and is a key intermediate in atmospheric hydrocarbon oxidation. It is one of the major primary sources of $\mathrm{HO}_{x}\left(\mathrm{HO}_{x}=\mathrm{HO}+\mathrm{HO}_{2}\right)$ radicals (Lowe and Schmidt, 1983; Fried et al., 1997; Hak et al., 2005; Seinfeld and Pandis, 2006) and it also serves as a large source in the global budget of $\mathrm{H}_{2}$ and $\mathrm{CO}$ (Price et al., 2007). Around $90 \%$ of global tropospheric $\mathrm{HCHO}$ is produced by the oxidation of methane $\left(\mathrm{CH}_{4}\right)$ and non-methane volatile organic compounds (NMVOCs), while direct emissions from biomass burning and fossil fuel combustion contribute to the remaining fraction (Carlier et al., 1986; Lee et al., 1998; Andreae and Merlet, 2001; Parrish et al., 2012). The known removal processes of $\mathrm{HCHO}$ include reaction with $\mathrm{OH}$ radicals, photolysis, deposition and aerosol uptake, of which the first two pathways are supposed to dominate (Zhou et al., 1996; Tie et al., 2001; Fried et al., 2003).

Budget analyses, however, reveal large discrepancies between observed $\mathrm{HCHO}$ concentrations and those predicted from models (Jacob, 2000; Wagner et al., 2002). Overpredictions of $\mathrm{HCHO}$ have been reported in a series of studies since the mid-1990s (Liu et al., 1992; Heikes et al., 1996; 
Jacob et al., 1996; Zhou et al., 1996). For example, a recent model study at a semi-rural site in southern China by $\mathrm{Li}$ et al. (2014) showed 2-5 times higher HCHO than observations. On the other hand, underpredictions have also been found in a few studies (Ayers et al., 1997; Jaegle et al., 2000; Weller et al., 2000; Kormann et al., 2003). The disagreement between model calculations and observations suggests an inadequate understanding of the $\mathrm{HCHO}$ budget and the existence of additional source/sink terms. For example, neglecting uptake of HCHO by aerosols/clouds (Zhou et al., 1996; Tie et al., 2001; Fried et al., 2003) may result in an overestimation, while insufficient consideration of NMVOCs oxidation processes may lead to underestimated production of HCHO (Wagner et al., 2002). So far the imbalance in the $\mathrm{HCHO}$ budget remains inconclusive.

Soil and soil-derived mineral dust could represent an important kind of surface regulating the budget of several trace gases and aerosols in the atmosphere (Usher et al., 2003; Kulmala and Petaja, 2011; Su et al., 2011; Oswald et al., 2013; Donaldson et al., 2014a). Understanding the interactions of $\mathrm{HCHO}$ with soil surfaces may help to explain the discrepancies and improve our understanding of the $\mathrm{HCHO}$ budget. Some field flux measurements have found HCHO emission from soil surfaces (DiGangi et al., 2011) while other studies suggested a net HCHO deposition on soil surfaces (Gray et al., 2014).

In this study, we investigate the HCHO uptake on soil surfaces using a coated-wall flow tube method. The experiments are performed under conditions relevant to the atmosphere, i.e., $\mathrm{HCHO}$ concentrations of $\sim 10$ to $40 \mathrm{ppbv}$ and relative humidities (RHs) of 0 to $70 \%$. The uptake coefficients $\gamma$ are determined by numerically solving the Cooney-Kim-Davis equation, which describes the loss of a trace species to the flow tube wall at laminar flow conditions (Murphy and Fahey, 1987). The results are discussed along with its underlying mechanisms and atmospheric implications.

\section{Methods}

\subsection{Sample preparation}

Soil samples were collected at a depth of $0-5 \mathrm{~cm}$ from a cultivated field site in Mainz, Germany $\left(49^{\circ} 59^{\prime} \mathrm{N}, 8^{\circ} 13^{\prime} \mathrm{E}\right)$. The soil $\mathrm{pH}$ was $\sim 7.5(1: 2$ soil / water $(v / v)$, Thermo Scientific, OrionStar A211 pH meter). The soil texture comprised $15 \%$ sand, $69 \%$ silt and $16 \%$ clay (wet sieving method) and the soil humus content was $3 \%$ (loss on ignition method) as analyzed by Envilytix GmbH (Wiesbaden, Germany). The collected samples were air-dried in the laboratory prior to grinding and sieving with a 120 mesh soil sieve. The sieved soil was autoclaved for $20 \mathrm{~min}$ at $394 \mathrm{~K}$ right before the flow tube coating procedure.

Different soil types are inhabited by different microbial communities being very sensitive to soil properties (e.g., soil water content, $\mathrm{pH}$, temperature, etc.). The applied wide range of changes in relative humidity within our experiments affects the soil water content, with respective impact on microbial activity. For a natural soil probe, the apportionment between the soil microbiological trace gas exchange and soil physicochemical effects would become vague, specifically in view of time-dependent patterns of microbial activity after changes in soil water content. The soil sterilization treatment eliminates the effects of microbiological activity on trace gas uptake/emission mechanism. The soil samples used in our study may serve as a soil proxy to study the physicochemical side of trace gas exchange, constituting a key element in regulating trace gas exchange at the atmosphere-soil interface (Donaldson et al., 2014b; VandenBoer et al., 2015). However, our results on sterilized soil samples cannot necessarily be considered representative for other and/or natural types of soils.

The coating procedure is one of the challenges in flow tube experiments. Manually coating the tube could be time consuming, and the coating thickness and homogeneity strongly depend on the operator. Here, an air-dried continuous rotating coating tool (ACRO) was developed to standardize the coating procedure and improve reproducibility and homogeneity (Fig. S1 in the Supplement). During the coating procedure, the tube was installed into the ACRO through two cylindrical fittings. One fitting was fixed to the inlet of the tube promoting tube rotation by means of a motor and a driving belt, while the other at the tube's outlet served only as a supporter not being fixed to the tube. The flow tube was normally placed horizontally but could also be tilted by adjusting the slope of ACRO (through a positioning screw). A drying air stream was piloted into the tube through a duct at the inlet connector. Before coating, we prepared a soil slurry by mixing dry soil with sterilized deionized water obtained from a Milli-Q system (18.2 M $\Omega \mathrm{cm}$, Millipore). The slurry was uniformly injected into an internally sandblasted glass tube which was then installed into the ACRO. The coated tube was rotated with a speed of $14 \mathrm{rpm}$ and dried overnight with a flow rate of $\sim 0.5 \mathrm{~L} \mathrm{~min}^{-1}$ of pure $\mathrm{N}_{2}(\mathrm{RH}=0 \%)$. The coating thickness/mass had been found to affect the trace gases uptake in earlier studies (Donaldson et al., 2014a). As the coating thickness increases, the uptake rate also increases due to enhanced number of surface sites available for gas uptake. Then the uptake rate moves up to a threshold level, where further increase in coating thickness doesn't affect the gas uptake. In order to exclude the influence of coating thickness, a relatively thick coating of $\sim 500 \mu \mathrm{m}$ was chosen for our experiments. Figure 1 shows the homogeneous soil cover thickness and structural details of the soil surface topography derived by scanning electron microscope (SEM). The good reproducibility of the experimental results as shown later also confirms the fair homogeneity and reproducibility of the coating. 

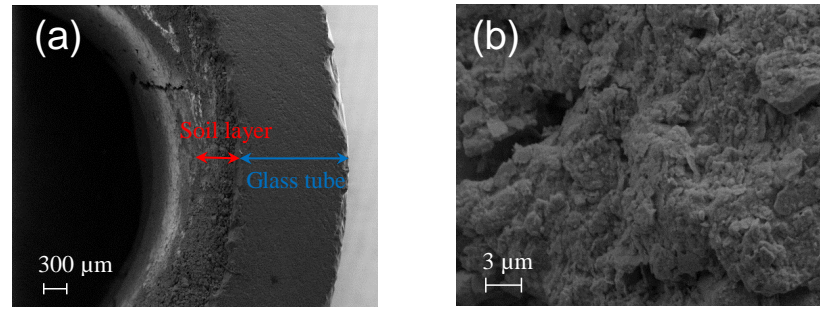

Figure 1. Characteristic morphology of coated soil layer observed by means of SEM (scanning electron microscope). (a) Flow tube cross-section view: the red arrow indicates the thickness of the soil layer and the blue arrow denotes the thickness of the glass tube. (b) View of the soil surface structure from above.

\subsection{Flow tube experiments}

The uptake of HCHO onto soil surfaces was measured by employing a coated-wall flow tube system (see Fig. 2). The system consisted of four parts: (1) a HCHO generator; (2) a humidification unit; (3) a flow tube and reference tube unit; and (4) a detection unit. HCHO was generated from a solid permeation tube (formaldehyde-para, rate: $91 \mathrm{ng} \mathrm{min}^{-1}$ at $60^{\circ} \mathrm{C}$, VICI Metronics Inc. USA) with $\mathrm{N}_{2}(\geq 99.999 \%)$ as the carrier gas. The RH was controlled by mixing humidified $\mathrm{N}_{2}$ with generated $\mathrm{HCHO}$ gas.

Two glass tubes (inner surface sandblasted) with identical dimensions (length: $250 \mathrm{~mm}$, i.d.: $7 \mathrm{~mm}$ ) were used for the uptake experiments. One tube was coated with soil samples and the other remained uncoated as a reference. Both tubes were placed in a cooling jacket in which a temperature of $296 \pm 1 \mathrm{~K}$ was maintained during the experiments. HCHO concentrations were measured by an AL $4021 \mathrm{HCHO}$ monitor (detection range: $100 \mathrm{ppt}-3 \mathrm{ppm}$, noise: $2 \%$ full scale, AERO LASER, Germany). It is an online HCHO analyzer for gaseous and liquid samples, based on the Hantzsch reaction. Gaseous HCHO is transferred into a liquid phase through a stripping coil, prior to reacting with Hantzsch reagents (ammonium acetate: for analysis, Merck, Germany; acetyl acetone: for analysis, Merck, Germany; and acetic acid (glacial): $100 \%$, Merck, Germany). The products show a strong fluorescence at $510 \mathrm{~nm}$, which is measured by a photomultiplier. The operation principle is described in detail elsewhere (Dasgupta et al., 1988). This analyzer has been used for field measurements and has shown high stability (Preunkert et al., 2013, 2015). The flow rate used for our lab experiments was $1 \mathrm{LSTP} \mathrm{min}^{-1}$. The analyzer was operated with liquid calibration gas measurement mode and was calibrated using standard $\mathrm{HCHO}$ solutions ( $37 \mathrm{wt} \%$ in $\mathrm{H}_{2} \mathrm{O}$, Sigma-Aldrich, USA).

Several flow tube experiments were carried out to examine different aspects of the uptake processes, e.g., reproducibility, RH dependence, and bi-directional exchange, etc. In each experiment, we adopted the following procedure: (1) flushing the freshly coated tube with pure $\mathrm{N}_{2}$; (2) flushing the uncoated reference tube with $\mathrm{HCHO}$; (3) flushing the freshly coated tube with HCHO. The first step was to detect background HCHO emission from soil. While the second step allowed for identification of potential uptake of HCHO on clean glass surface, the third step was dedicated to investigate HCHO uptake by the soil surface, from which uptake coefficients can be derived. To check the stability of the HCHO monitor and generator, we also performed zero calibrations for the monitor and measured the generated $\mathrm{HCHO}$ concentrations before and after each experiment. As a wide range of $\mathrm{RH}$ conditions $(0-70 \%)$ was applied in the uptake experiments, the potential effect of water molecules on the generated $\mathrm{HCHO}$ concentration and background (zero air) concentration was examined. At the outlet of the stripping coil, the sample air was saturated to $100 \% \mathrm{RH}$ at $10^{\circ} \mathrm{C}$. Depending on the inlet air RH (at room temperature) the stripping solution would gain (condensation) or lose (evaporation) water according to the gas/liquid phase equilibrium (Junkermann and Burger, 2006). The bias in calculated HCHO concentrations was within $\pm 3 \%$. To check the RH effect on measured $\mathrm{HCHO}$ concentration under varying RH conditions, we occasionally compared the observed concentrations with data derived from the certified permeation rate of the permeation tube and the measured gas flow rate (gas phase calibration method). The observed total bias, assumed to characterize the instrument's accuracy was within $\pm 5 \%$. Moreover, the instrument's zero air background was observed to increase gradually when increasing RH from 0 to $50 \%$, and decreased when further increasing RH beyond $70 \%$. This could be due to the RH effect on the measurement principle, inlet surface effects, or aging of peristaltic tubes, stripping solution and Hantzsch solution (Kaiser et al., 2014). To account for the influence of changed background on measured HCHO concentration, the background was checked at the beginning and end of each experiment and the measured HCHO concentrations were corrected based on observed background values. On the other hand, well-known ozone interferences (Rodier and Birks, 1994; Kormann et al., 2003) were not of any concern for our studies, as the applied carrier gas was free of ozone.

\subsection{Determination of uptake coefficients}

The goal of our kinetic experiments is to determine the uptake coefficients $\gamma$. The parameter $\gamma$ is defined as the fraction of effective collisions between $\mathrm{HCHO}$ and the soil surface that leads to loss of $\mathrm{HCHO}$ due to physical or chemical processes. For investigations on trace gas uptake kinetics using flow tubes, a method, designated the CKD solution (Murphy and Fahey, 1987), is commonly applied to account for radial and axial diffusion effects. Here we develop a new method rather than using the interpolated values provided in CKD method. As our method is based on the CKD, it can be specified as a CKD-based method (CKD-B). For the details of CKD-B, see Appendix A. In our experiment, 


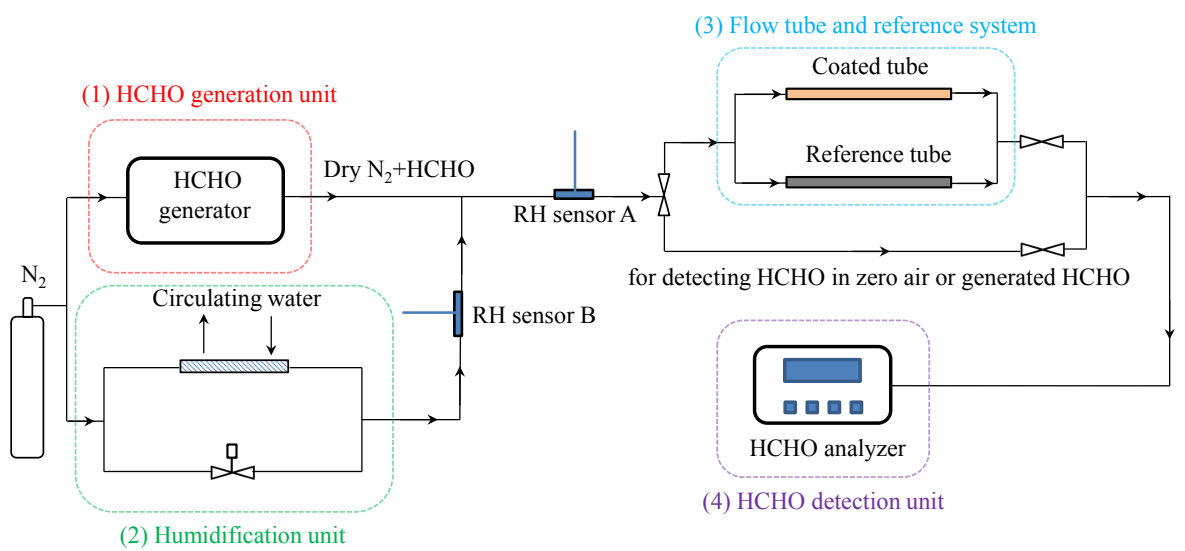

Figure 2. Schematic of the experimental setup. For details see text.

the Reynolds number $R e$ is $\sim 200$ ensuring the laminar flow conditions which require $\operatorname{Re}<\sim 2100$ (Murphy and Fahey, 1987). The total flow tube length is $25 \mathrm{~cm}$ and full development of laminar flow is achieved within $\sim 5 \mathrm{~cm}$ for our setup. The uptake coefficients reported here are based on the geometric surface area of the soil sample, considering that in atmospheric models soil microstructure is not taken into account. In order to facilitate modelling, the calculated uptake coefficients as a function of initial $\mathrm{HCHO}$ concentration, relative humidity and uptake time period are summarized in Table S1 in the Supplement. The specific surface area of the soil sample, however, was also measured using a water vapor adsorption method based on the Brunauer-EmmettTeller (BET) adsorption theory (Brunauer et al., 1938) being $18.9 \pm 1.3 \mathrm{~m}^{2} \mathrm{~g}^{-1}$. For calculating this BET surface area, the mass of the adsorbed water on soil sample after equilibrium with pre-defined RH levels was determined by a nondispersive infrared (NDIR) gas analyzer (type: Li-6262, LICOR Biosciences Inc.) operated in differential mode. This BET surface area is comparable to that in other reports on similar soil types, e.g., $12-15 \mathrm{~m}^{2} \mathrm{~g}^{-1}$ (Kahle et al., 2002) and $8-19 \mathrm{~m}^{2} \mathrm{~g}^{-1}$ (Punrattanasin and Sariem, 2015). Accounting for the BET surface area would decrease $\gamma$ by a factor of $10^{4}$ in our case.

\section{Results and discussion}

\subsection{HCHO uptake reproducibility on soil}

Chamber experiments have often been used to investigate the soil emission or uptake of trace gases. A common problem of chamber studies is that the results are not reproducible. Even for the same soil samples and experimental setup, the results may still differ from each other. This lack of reproducibility deteriorates the interpretation, extrapolation and application of experimental results.

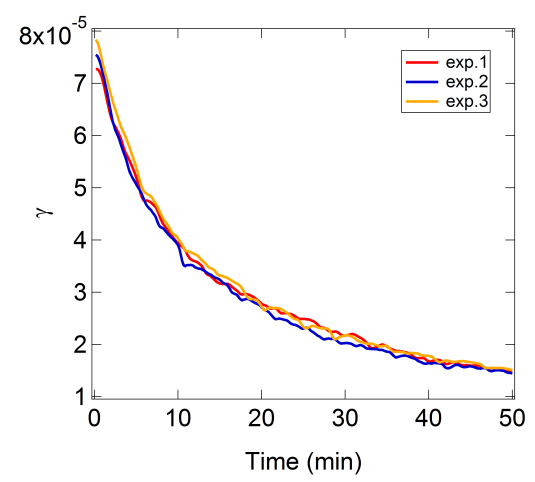

Figure 3. Effect of repeated uptake and emission on soil uptake coefficients within the uptake time range of $50 \mathrm{~min}$ at $50 \% \mathrm{RH}$.

The change of soil microbiological activities and soil micro-structure seems to be the two most probable reasons leading to non-reproducible results. If that's the case, sterilized soil with a well-defined structure/geometry can avoid these influences and present reproducible results. To test it, we performed three uptake experiments for the same soil sample under the same RH conditions. Before each experiment, the coated flow tube was flushed with pure $\mathrm{N}_{2}$ (HCHOfree) until HCHO release ceased.

As shown in Fig. 3, almost identical uptake coefficients are determined from three experiments (each lasted for $50 \mathrm{~min}$ ) at $\mathrm{RH}$ of $50 \%$ and $\mathrm{HCHO}$ concentration of $\sim 35 \mathrm{ppbv}$. The reproducibility gives confidence in the kinetic parameter $\gamma$ determined from the flow tube approach.

\subsection{HCHO uptake on soil and temporal variation}

Variation of uptake coefficients with time is a key question for evaluating the atmospheric relevance of surface uptake. Fast initial uptake can be unimportant if it quickly slows down due to consumption or occupation of reactive sites on surfaces (Kalberer et al., 1999). In this work, two $8 \mathrm{~h}$ uptake 

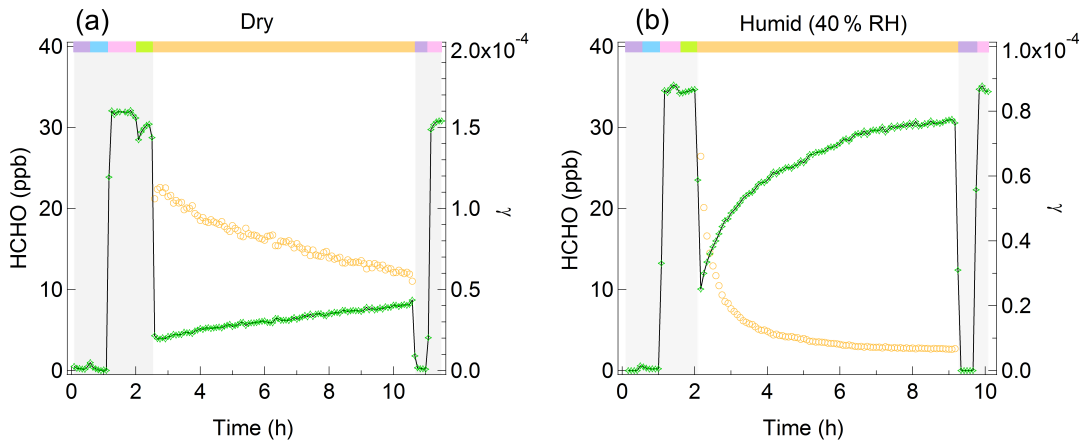

Figure 4. Observed HCHO (green diamonds) at the flow tube outlet and uptake coefficients (orange circles) as (a) $\sim 32 \mathrm{ppb}$ of $\mathrm{HCHO}$ is exposed to soil at $0 \% \mathrm{RH}$ and (b) $\sim 35 \mathrm{ppb}$ of $\mathrm{HCHO}$ is exposed to soil at $40 \% \mathrm{RH}$. The bars with different colors indicate the time periods corresponding to different gas supply: purple bars $\left(\mathrm{N}_{2}\right)$, blue bar $\left(\mathrm{N}_{2}\right.$ after flowing through the soil-coated tube), pink bars (generated $\mathrm{HCHO}$ ), green bar ( $\mathrm{HCHO}$ after flowing through reference tube), orange bar (HCHO after flowing through soil-coated tube).

experiments were performed to check the temporal variability of the HCHO uptake coefficients.

We first investigated the case under dry conditions $(\mathrm{RH}$ of $\sim 0 \%$ ), in which $\sim 32 \mathrm{ppb}$ of HCHO supplied by the $\mathrm{HCHO}$ generator was flushed through the flow tube. As shown in Fig. 4a, the largest $\mathrm{HCHO}$ uptake and decrease of $\mathrm{HCHO}$ concentration are found in the beginning of the uptake experiment. Within the $8 \mathrm{~h}$ experiment, $\gamma$ is reduced from $(1.1 \pm 0.05) \times 10^{-4}$ to $(5.5 \pm 0.4) \times 10^{-5}$. To extend the generality of such dependence, we also conducted the same experiment but at RH of $40 \%$. As shown in Fig. 4b, the result reveals an even faster decay of $\gamma$ over time suggesting an important role of water vapor in controlling the trace gas exchange at the atmosphere-soil interface.

\subsection{Relative humidity $(\mathrm{RH})$ effect}

Water vapor has been suggested to influence the surface uptake for a variety of surface materials. On the one hand, it may compete for the reactive sites with other species and reduce their uptake (Ruiz et al., 1998; Goss et al., 2004; Donaldson et al., 2014a). On the other hand, the condensed water may attract more water-soluble or hydrophilic molecules and enhance the uptake (Pei and Zhang, 2011). To better understand the role of water molecules, we examined the RH dependence of uptake coefficients. Each experiment lasted for $50 \mathrm{~min}$ with the same setup as the aforementioned $8 \mathrm{~h}$ experiments.

Figure 5 shows the dependence of uptake coefficients of HCHO under different RHs. The highest value is achieved at dry conditions ( $\mathrm{RH}$ of $\sim 0 \%$ ) and doesn't decrease much within the 50-min experiment. Increasing $\mathrm{RH}$ results in a sharp decrease of $\gamma$, until reaching a RH threshold level of $\sim 30 \%$. Above $30 \% \mathrm{RH}, \gamma$ becomes almost independent of $\mathrm{RH}$. This RH effect could be expected for a longer uptake time period (e.g., $8 \mathrm{~h}$ ), as the uptake coefficients always show a large difference between dry and humid conditions during the $8 \mathrm{~h}$ uptake experiments (Fig. $4 \mathrm{a}$ and b). For the de-

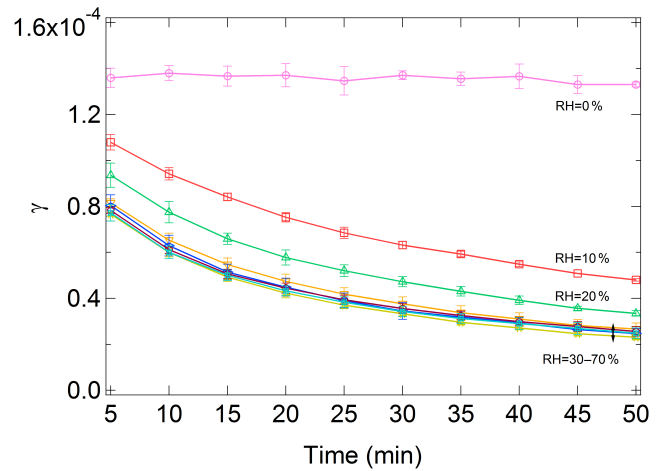

Figure 5. Uptake coefficients variation as a function of uptake time, under different RHs. The error bars represent the standard deviation of three replicate experiments.

tailed mechanism of the RH influence on $\mathrm{HCHO}$ uptake, see Sect. 3.6.

\subsection{Concentration effect}

We also investigated the dependence of the uptake coefficients on initial HCHO concentrations, under dry and humid conditions (Fig. 6). Under dry conditions, higher HCHO concentrations $(20-40 \mathrm{ppb})$ lead to significantly reduced uptake coefficients. The HCHO molecules themselves exert a competition for reactive sites. This effect almost ceases under humidified conditions. As the number of water molecules is far more than that of $\mathrm{HCHO}$ and they both show competitive adsorption behavior on soil, it is conceivable that this concentration effect is weakened by increasing RH to $40 \%$, further confirming the strong influence of water on the HCHO uptake.

Such a dependence on the initial concentrations of analytes under low RH conditions had already been reported by other researchers. Sassine et al. (2010) investigated the HCHO uptake kinetics on $\mathrm{TiO}_{2}$ mineral coatings and found that the 

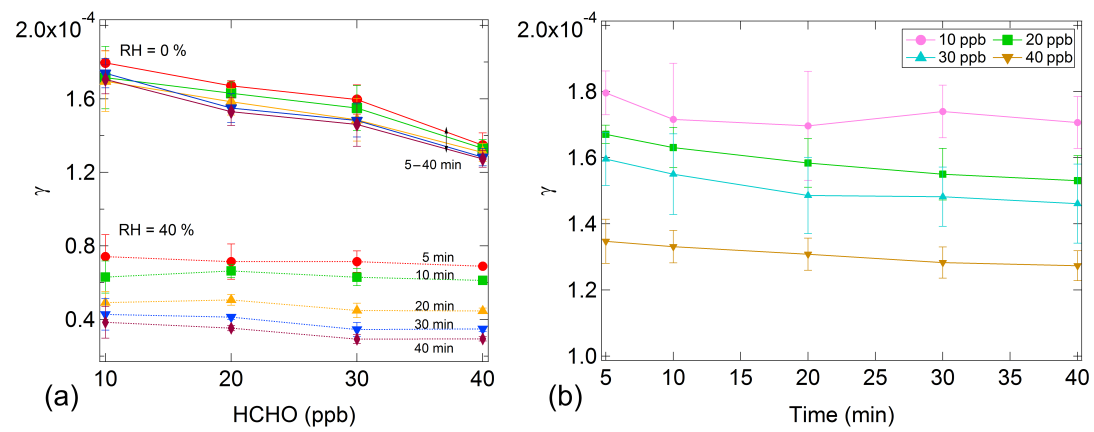

Figure 6. Dependence of uptake coefficients on initial HCHO concentrations at 0 and $40 \% \mathrm{RH}$, after uptake time periods of 5 min (red), $10 \mathrm{~min}$ (green), $20 \mathrm{~min}$ (orange), $30 \mathrm{~min}$ (blue) and $40 \mathrm{~min}$ (purple) (a); and uptake coefficients as a function of uptake time period at $0 \% \mathrm{RH}$ (b); both under ambient pressure and $296 \mathrm{~K}$. The error bars represent the standard deviation of three replicate experiments.

inverse of the uptake rate depended linearly on the inverse of the HCHO inlet concentrations. Wang et al. (2012) measured the uptake of $\mathrm{NO}_{2}$ onto soil using a coated-wall flow tube and also observed that uptake coefficients were negatively dependent on $\mathrm{NO}_{2}$ gas phase concentrations. They both gave explanations based on the Langmuir-Hinshelwood mechanism, in which gas molecules compete for the adsorption sites and the adsorbed molecules undergo following reactions. At higher HCHO concentrations (20-40 ppb) or/and higher water vapor partial pressure $(\mathrm{RH}=40 \%)$, the soil surface becomes more easily covered by adsorbed $\mathrm{HCHO}$ or/and $\mathrm{H}_{2} \mathrm{O}$ molecules that had not yet reacted, resulting in lower probability of successful collisions between HCHO and the soil surface and thus a lowering of the uptake coefficient.

\subsection{Reversibility of HCHO uptake}

The decay of initial uptake is a common feature for trace gas uptake on different surfaces. It can be explained by different mechanisms, e.g., a process dominated by adsorption and chemical reactions; or a process governed by surface and bulk reactions. To explore the underlying mechanism, we conducted a back-flushing experiment and investigated the reversibility of $\mathrm{HCHO}$ uptake.

We first performed a standard experiment by flushing HCHO through a coated flow tube with RH of $50 \%$. Then the same tube was flushed with pure $\mathrm{N}_{2}$ ( $\mathrm{HCHO}$ free) and the amount of HCHO released elucidated potential uptake reversibility. Figure 7 shows that indeed the $\mathrm{HCHO}$ adsorbed by soil can be released back to the gas phase. The areas enclosed by the uptake and emission curves (orange area $S_{\mathrm{a}}$ and yellow area $S_{\mathrm{e}}$ ) represent the amount of $\mathrm{HCHO}$ adsorbed and re-emitted by the soil, respectively. $S_{\mathrm{a}}$ and $S_{\mathrm{e}}$ could be calculated by curve fitting and integration. As the emission curve doesn't end with infinitely approaching the zero air signal, a fitted curve is used to consider this infinite decrease of HCHO signal and infer the total amount of re-emitted HCHO, reflected by $S_{\mathrm{e}}$. Two functions are tested for emission curve fitting (parameters as detailed in Table 1).
These fitting functions are derived on the basis of $\mathrm{HCHO}$ mass conservation in the flow tube, that is, the increase in gas flow $\mathrm{HCHO}$ concentration equals the $\mathrm{HCHO}$ released from the soil due to desorption and/or oligomer dissociation at the same time. The mass decay rate of $\mathrm{HCHO}$ on the soil which is determined by $\mathrm{HCHO}$ mass $M$ and the net rate coefficient $k$ can be expressed as $\mathrm{d} M / \mathrm{d} t=-k \times M^{n}(k$ reflects the net effect of emission rate and dissociation reaction rate on the soil surface; $n$ means the apparent order of reactions between $\mathrm{HCHO}$ molecules (e.g., oligomerization), if $n=1$, no reactions between $\mathrm{HCHO}$ molecules). Note that the HCHO mass decay mentioned here only takes into account processes which could re-emit HCHO into the gas phase (reversible reactions) rather than those converting $\mathrm{HCHO}$ into other products (irreversible reactions), as the emission curve in Fig. 7 only represents the reversible fraction. By solving the above differential equation and further taking the derivative of $M(t)$, the $\mathrm{HCHO}$ concentration $C$ in the gas flow can be identified as a function of time $t$, as shown in Table 1 $(C=f(x), t=x)$. Table 1 compares two fitting functions, with the first one only accounting for zero and first order reactions and the second one further involving second order reactions. The latter provides better fitting results, implying the existence of physical/chemical interactions between adsorbed HCHO molecules on the soil surface (e.g., hydration and oligomerization). Thus, the second fitting function is applied to infer the total amount of re-emitted HCHO. The reemitted $\mathrm{HCHO}$ is $(70 \pm 15) \%$ ((average \pm 1 standard deviation) \%) of that adsorbed in the uptake experiment (Fig. 7), while the residual $(30 \pm 15) \%$ remains in the soil. This partial reversibility suggests that $\mathrm{HCHO}$ uptake on soil is a combination of adsorption/desorption and chemical reactions.

To further explore the reasons for this partial reversibility, we conducted an energy dispersive X-ray (EDX) analysis of the soil sample. As shown in Fig. S2, inorganic elements (mainly exist as minerals) dominate the soil composition and the low fraction of carbon is consistent with the measurement of soil organic matter (Sect. 2.1). Among the inorganic elements, silicon is most abundant followed by alu- 
Table 1. Parameters of fitting functions.

\begin{tabular}{lrrrrr}
\hline Functions & \multicolumn{3}{c}{ Coefficients (with 95\% confidence bounds) } & Goodness of fit \\
\cline { 2 - 6 } & $a$ & $b$ & $c$ & $d$ & $R^{2}$ \\
\hline$f(x)=$ & $-1.18 \times 10^{-8}$ & 39.7 & 0.616 & 0.944 \\
$a+b \times \exp (-c \times x)$ & & $(38.35,41.04)$ & $(0.607,0.625)$ & & \\
\hline$f(x)=$ & $-1.15 \times 10^{-4}$ & 3.13 & 0.214 & 0.140 & 0.264 \\
$a+b \times \exp (-c \times x)$ & $(-0.456,0.455)$ & $(2.35,3.91)$ & $(0.094,0.333)$ & $(0.121,0.160)$ & $(0.221,0.308)$ \\
$+d \times(e-d \times x)^{-2}$ & & & & 0.998 \\
\hline
\end{tabular}

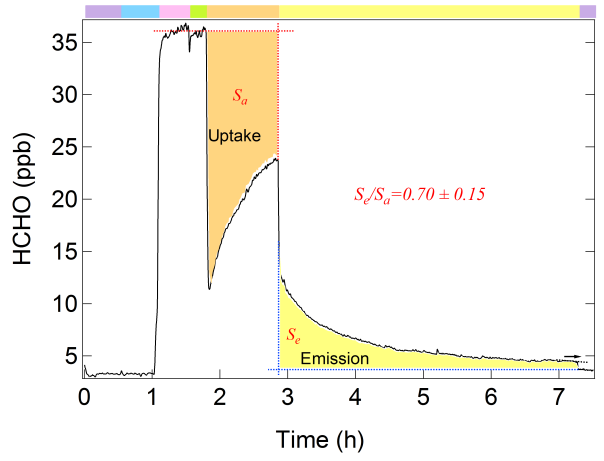

Figure 7. Reversible uptake of $\mathrm{HCHO}$ onto soil at $50 \% \mathrm{RH}$. The yellow bar represents the time period when flushing with $\mathrm{N}_{2}$ just after the uptake experiment; other color bars as in Fig. 4.

minium, calcium and iron, with their contents (wt \%) being $\sim 64, \sim 13, \sim 6.3$ and $\sim 5.7 \%$, respectively. The partial reversibility can be interpreted by the different uptake ability of various components. Carlos-Cuellar et al. (2003) reported that $\mathrm{HCHO}$ uptake was completely reversible on $\mathrm{SiO}_{2}$ but only partly $(<1-15 \%)$ reversible on $\alpha-\mathrm{Al}_{2} \mathrm{O}_{3}$ and $\alpha-\mathrm{Fe}_{2} \mathrm{O}_{3}$. $\mathrm{Xu}$ et al. (2011) investigated the heterogeneous reactions of $\mathrm{HCHO}$ on the surface of $\gamma-\mathrm{Al}_{2} \mathrm{O}_{3}$ particles and concluded that the adsorbed $\mathrm{HCHO}$ was firstly oxidized to dioxymethylene and further to formate. The fraction of silicon of $\sim 70 \%$ (silicon content divided by the total amount of all inorganic elements) in the soil investigated here closely resembles the fraction of $\mathrm{HCHO}$ desorbed $((70 \pm 15) \%)$ from soil at zero air conditions.

Since mineral particles occupy the major volume (approximately 45-49\%) of soils (DeGomez et al., 2015) and silicon minerals (e.g., silicon oxides) are fairly common in mineral particles, the partial reversibility of HCHO uptake as shown in Fig. 7 may be expected as a general feature for other similar types of soils.

\subsection{Uptake mechanism}

Pore diffusion and surface processes could both account for the uptake of $\mathrm{HCHO}$ by soils. For pore diffusion within soils, the time scale depends on the thickness of the soil layer and the specific diffusion coefficients. Morrissey and Grismer (1999) reported typical macroscopic diffusion coefficients of VOCs ranging from $10^{-2}$ to $10^{-4} \mathrm{~cm}^{2} \mathrm{~min}^{-1}$ for clay minerals. However, the effective diffusion coefficients of VOCs in soils depend on soil properties, e.g., soil porosity, pore geometry, grain size, soil water content etc. and on VOCs characteristics, e.g., molecular size, Henry's law constant, solubility etc. (Batterman et al., 1996). Adopting the above range and utilizing Fick's second law of diffusion for our experimental case, we estimate a time scale for HCHO diffusing through the soil layer from tens of seconds to several minutes. This time scale is much less than that for our uptake experiments $(8 \mathrm{~h})$, indicating that pore diffusion is not the limiting factor of uptake. In this sense, the uptake of $\mathrm{HCHO}$ by soil could be described by a mechanism including both adsorption/desorption and reactions of adsorbed $\mathrm{HCHO}$ on the soil surface.

For the adsorption process (Reaction R1), gas phase $\mathrm{HCHO}, \mathrm{HCHO}(\mathrm{g})$, can react with a reactive site $S$ on the soil surface and become adsorbed by soil. The adsorbed $\mathrm{HCHO}$ (ads) can desorb into gas phase and release the reactive site. Once adsorbed, individual $\mathrm{HCHO}$ molecules may react with adsorbed water (hydration) and/or further combine with other HCHO to form oligomers (Toda et al., 2014). On the other hand, $\mathrm{HCHO}$ (ads) can also be converted to other products through chemical reactions (Reaction R2).

$\mathrm{HCHO}(\mathrm{g})+S \underset{k_{d}}{\stackrel{k_{a}}{\rightleftarrows}} \mathrm{HCHO}($ ads $) \underset{k_{p}}{\stackrel{k_{o}}{\rightleftarrows}}$ oligomers

$\mathrm{HCHO}($ ads $) \stackrel{k_{r}}{\rightarrow}$ products

$\mathrm{H}_{2} \mathrm{O}+S \underset{k_{d}^{\prime}}{\stackrel{k_{a}^{\prime}}{\rightleftarrows}} \mathrm{H}_{2} \mathrm{O}($ ads $)$

$\mathrm{H}_{2} \mathrm{O}$ would also undergo adsorption/desorption processes (Reaction R3), occupy the reactive site and compete with HCHO. The competing effect of water molecules depends on the number of water monolayers on the soil surface. Ong and Lion (1991a) classified such effect into three regimes in their study of trichloroethylene (TCE) sorption on soil minerals. According to this mechanism, the first regime (regime I) is from dry conditions to one monolayer coverage of water on 


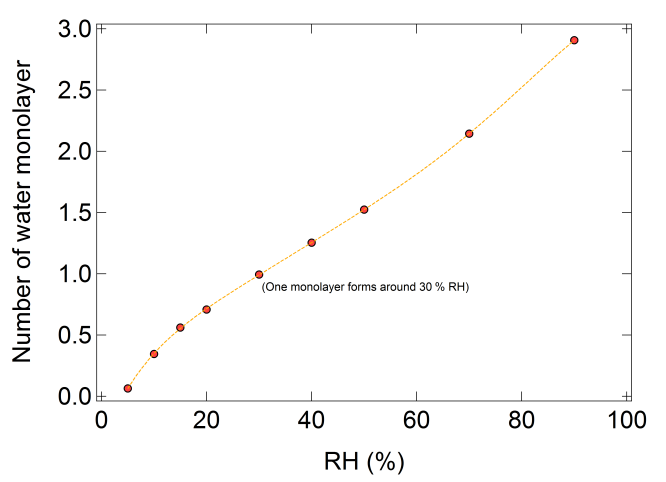

Figure 8. Number of soil surface water monolayers, based on gravimetric analysis of water uptake and soil surface area determined by the BET method.

the soil surface, where direct soil-gas sorption is evident with strong competition between water and $\mathrm{HCHO}$ for adsorption sites on soil. The second regime (regime II) corresponds to one to five monolayers of water molecules, with likely interactions between $\mathrm{HCHO}$ and water including sorption of $\mathrm{HCHO}$ onto surface-bound water that may lead to hydration and further oligomerization of $\mathrm{HCHO}$, and limited dissolution into these monolayers. The third regime (regime III) starts from approximately five layers of water molecules up to the water holding capacity of soil, where the sorption of $\mathrm{HCHO}$ is dominated by condensed water on soil with respective dependence on Henry's law. In this regime, HCHO hydrates into methylene glycol or into polyoxymethylene glycols (oligomerization; Toda et al., 2014) which might further enhance the uptake of $\mathrm{HCHO}$ on soil.

Based on our BET experiment, one water monolayer forms at $\sim 30 \%$ RH (Fig. 8) which is consistent with those values (20-30\%) reported by Donaldson et al. (2014a), Lammel (1999) and Goss (1993) retrieved across different soil types. For $\mathrm{RH} \leq 30 \%$, the HCHO sorption lies in the regime I, and water molecules show a large competing effect with $\mathrm{HCHO}$ as demonstrated by the strong negative dependence of $\gamma$ on the RH (Fig. 5). For RH $>30 \%$, the water effect moves to the regime II. In this regime the adsorbed water is highly structured and modified by interactions with the soil mineral surface (Goss, 1992), and the surface area available for gas sorption is also kept constant (Goss et al., 2004). The constant surface area could explain the relatively stable uptake coefficients of $\mathrm{HCHO}$ observed between 30 and $70 \% \mathrm{RH}$ as shown in Fig. 5. We haven't reached regime III in our experiment (which would require a RH $>90 \%$ ). According to Ong and Lion (1991a), the uptake in regime III follows Henry's law. So increasing RH will increase the solvent volume (or number of water molecules) on the soil surface and thus increase the adsorption capacity.

In addition to the interactions between $\mathrm{HCHO}$ and water molecules in different regimes mentioned above, the rates

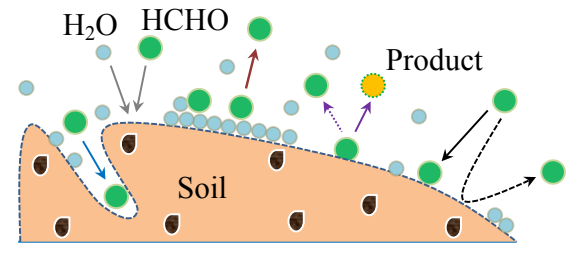

Figure 9. Schematic of HCHO uptake by soil surfaces.

of adsorption/desorption vs. the chemical reaction rates also come into play in the net exchange of $\mathrm{HCHO}$.

During the uptake process, the rate expression for $\mathrm{HCHO}$ loss from the gas phase can be given by the following:

$-\frac{\mathrm{d}[\mathrm{HCHO}(\mathrm{g})]}{\mathrm{d} t}=k_{a}[\mathrm{HCHO}(\mathrm{g})][S]-k_{d}[\mathrm{HCHO}(\operatorname{ads})]$.

From the point of kinetic gas theory, this loss rate could also be described as follows:

$$
\begin{aligned}
-\frac{\mathrm{d}[\mathrm{HCHO}(\mathrm{g})]}{\mathrm{d} t} & =\frac{\gamma_{\mathrm{HCHO}} \omega_{\mathrm{HCHO}}}{4} \times \frac{A_{\mathrm{s}}}{V} \times[\mathrm{HCHO}(\mathrm{g})] \\
& =\frac{\gamma_{\mathrm{HCHO}} \omega_{\mathrm{HCHO}}}{2 r}[\mathrm{HCHO}(\mathrm{g})],
\end{aligned}
$$

where $\gamma_{\mathrm{HCHO}}$ is the uptake coefficient of $\mathrm{HCHO}, \omega_{\mathrm{HCHO}}$ is the thermal velocity of $\mathrm{HCHO}, A_{\mathrm{s}}$ is the geometric surface area of the soil, $V$ and $r$ are the volume and radius of the flow tube, respectively. Equating Eqs. (1) and (2) yields a positive correlation between $[S]$ and $\gamma_{\mathrm{HCHO}}$. Increase of $\mathrm{RH}$ would decrease $[S]$ due to Reaction (R3) and thus further reduce the value of $\gamma_{\mathrm{HCHO}}$. This further explains the $\mathrm{RH}$ dependence of $\gamma$ as shown in Sect. 3.3.

For the variation of adsorbed $\mathrm{HCHO}$ on soil surface during the uptake, the adsorption/desorption, oligomerization/dissociation and chemical reactions are all considered and the rate is given as follows:

$$
\begin{aligned}
& \frac{\mathrm{d}[\mathrm{HCHO}(\mathrm{ads})]}{\mathrm{d} t}=k_{a}[\mathrm{HCHO}(\mathrm{g})][S]-k_{d}[\mathrm{HCHO}(\mathrm{ads})] \\
& +\left(k_{p}-k_{o}\right)[\text { oligomers }]-k_{r}[\mathrm{HCHO}(\mathrm{ads})] .
\end{aligned}
$$

At the start of uptake, [HCHO(ads)] is zero and only the forward reaction of adsorption is relevant. HCHO adsorbed onto the soil surface would accumulate and increase the rates of desorption, oligomerization and chemical reactions. [HCHO(ads)] will continuously grow until a steady state is established, in which case $\mathrm{d}[\mathrm{HCHO}(\mathrm{ads})] / \mathrm{d} t=0$ and the net loss of $\mathrm{HCHO}$ in the gas phase is dominated by chemical reactions on soil. Meanwhile, the oligomerization of adsorbed HCHO may serve as a temporary buffer, storing or releasing $\mathrm{HCHO}$ on soil. On the other hand, the emission of $\mathrm{HCHO}$ from soil can also be limited by dissociation of these oligomers and dehydration of HCHO hydrates, this may explain the prolonged emission curve found in Fig. 7. 


\section{Conclusions}

We investigated the HCHO uptake on soil surfaces by a coated-wall flow tube method. Soil exhibits strong capacity for absorbing gaseous $\mathrm{HCHO}$, with initial $\gamma$ ranging from $(1.4 \pm 0.08) \times 10^{-4}$ at $0 \% \mathrm{RH}$ to $(3.0 \pm 0.3) \times 10^{-5}$ at $70 \% \mathrm{RH}$ based on the geometric soil surface. Because of simultaneously acting adsorption/desorption processes, $\gamma$ shows a strong temporal dependence with an initial peak and subsequent decay until a steady state is reached. We also find a clear RH dependence of $\gamma$, especially in the low RH range (e.g., $\leq 30 \%$, under ambient pressure and temperature conditions) and little RH effect at $\mathrm{RH}>30 \%$. The RH dependence of HCHO uptake can be explained by a transition of uptake pathways. Under low RH and water coverage (less than one monolayer) water molecules compete with gaseous $\mathrm{HCHO}$ for the adsorption sites on soil, while under high RH the soil surface is fully covered with water molecules providing a near constant amount of surface adsorption sites. Besides $\mathrm{HCHO}$, a similar effect of RH had been reported for the soil uptake of other VOCs (Chiou and Shoup, 1985; Smith et al., 1990; Ong and Lion, 1991b, a; Pennell et al., 1992; Goss, 1993; Unger et al., 1996; Ruiz et al., 1998).
Our results also show that HCHO uptake on soil is a partially reversible process involving both adsorption/desorption and chemical reactions (see Fig. 9). The adsorption/desorption reveals a bi-directional exchange on soil surfaces in which soil could serve either as a source or as a sink depending on ambient conditions and trace gas concentrations. Because of the strong diurnal variability of ambient $\mathrm{HCHO}$ concentrations, soil water content, temperature and hence relative humidity, $\mathrm{HCHO}$ exchange at soil surfaces may quickly change its sign in a diurnal course as suggested for other trace gases such as HONO (Su et al., 2011; VandenBoer et al., 2015). The adsorption/desorption equilibrium and the competition effects of water vapor are likely to influence the atmosphere-soil exchange of other trace gases as well.

\section{Data availability}

The underlying research data can be accessed upon contact with Yafang Cheng (yafang.cheng@mpic.de) or Guo Li (guo.li@mpic.de). 
Appendix A: Development and evaluation of the CKD-B method

The differential equation describing the analyte $\mathrm{HCHO}$ for our experimental case) concentration $C$ as a function of axial and radial position $(z, r)$ in a flow tube, and a new boundary condition proposed in CKD are given as follows:

$$
\begin{aligned}
& u \frac{\partial C}{\partial z}=D \frac{1}{r} \frac{\partial}{\partial r}\left(r \frac{\partial C}{\partial r}\right) \\
& -\left.D \frac{\partial C}{\partial r}\right|_{\text {wall }}=C \frac{\bar{v}}{4} \frac{\gamma}{1-\left(\frac{\gamma}{2}\right)} \\
& -\left.\frac{\partial C}{\partial r^{*}}\right|_{r^{*}=1}=N_{\text {Shw }} C \text { with } r^{*}=\frac{r}{R},
\end{aligned}
$$

in which $u$ is the axial flow velocity and $D$ is the gas diffusion coefficient under experimental conditions. $\bar{v}$ is the mean molecular speed and $\gamma$ is the uptake coefficient. $N_{\text {Shw }}$ is the Sherwood number and $R$ is the radius of the flow tube.

Equation (A2) shows that $C_{\text {wall }}$ (the concentration at the wall) is required to determine $\gamma$. However, the radial diffusion needs time and may result in a concentration gradient in the radial direction. Since we can only measure the averaged concentration instead of $C_{\text {wall }}$, the determination of $\gamma$ cannot be achieved unless the $C$ profile is determined first (Behnke et al., 1997; Monge et al., 2010; Sassine et al., 2010; Kebede et al., 2013) (for details see reference Murphy et al., 1987). Therefore the factor of $\gamma /(1-\gamma / 2)$ rather than simply $\gamma$ is used by Murphy et al. (1987) for a correction to the wall collision rate in the presence of a concentration gradient near the wall. Equation (A3) is taken as a dimensionless form of Eq. (A2).

For each given $\gamma$, a differential equation provided in CKD method (Eq. A1) can be solved for a $C$ profile and the functional relationship between transmittance of the analyte in the flow tube $\left(C_{\text {out }} / C_{\mathrm{in}}, C_{\mathrm{out}}\right.$, and $C_{\mathrm{in}}$ correspond to the concentrations of analyte at the outlet and the inlet of the flow tube, respectively) and $\gamma$ (strictly the Sherwood number $N_{\text {Shw }}$ as detailed in reference Murphy and Fahey, 1987) can be established. Then by measuring the transmittance, we can determine the desired uptake coefficients. It can be conceived that the $\gamma$-transmittance relation also depends on flow rate and the flow tube dimensions. Therefore, Murphy and Fahey (1987) provided a table of coefficients for a range of these parameters. When conditions were not available from the table, interpolation was often used in previous studies.

Here we directly solve the differential equation with numerical methods (code provided in the Supplement) rather than using interpolated values. As this operation is based on the CKD method, it can be specified as a CKD-based method (CKD-B), and this nomenclature is adopted above. More recently, another new analytical method has been derived by Knopf, Pöschl and Shiraiwa (KPS), based on a recently developed kinetic flux model framework and models discribing interactions of gas species with aerosol particles (Knopf et al., 2015) (for details see references therein). As the KPS method provides efficient and robust analyses and predictions of gas and particle uptake in flow tube experiments encountering diffusion limitation, here, we make a comparison between CKD-B and KPS. Figure S3 shows that both methods agree very well for deriving the dependence of transmittance $C_{\text {out }} / C_{\text {in }}$ on $\gamma$, under the specific flow rate and flow tube dimensions in our experimental case. To further test the accuracy of CKD-B method, the dependence of transmittance $C_{\text {out }} / C_{\text {in }}$ on the Sherword number $\left(N_{\text {Shw }}\right)$ is compared between CKD-B and CKD as well. Figure S4 shows a good agreement between results from CKD (red dots) and CKD-B (black line). 


\section{The Supplement related to this article is available online at doi:10.5194/acp-16-10299-2016-supplement.}

Acknowledgements. This study was supported by the Max Planck Society (MPG) and National Natural Science Foundation of China (41330635). Guo Li acknowledges the financial support from the China Scholarship Council (CSC). We are grateful to Sorowka Antje for her help with the SEM and EDX analysis of the soil sample.

The article processing charges for this open-access publication were covered by the Max Planck Society.

Edited by: F. Keutsch

Reviewed by: two anonymous referees

\section{References}

Andreae, M. O. and Merlet, P.: Emission of trace gases and aerosols from biomass burning, Global Biogeochem. Cy., 15, 955-966, 2001.

Ayers, G. P., Gillett, R. W., Granek, H., deServes, C., and Cox, R. A.: Formaldehyde production in clean marine air, Geophys. Res. Lett., 24, 401-404, 1997.

Batterman, S., Padmanabham, I., and Milne, P.: Effective gas-phase diffusion coefficients in soils at varying water content measured using a one-flow sorbent based technique, Environ. Sci. Technol., 30, 770-778, 1996.

Behnke, W., George, C., Scheer, V., and Zetzsch, C.: Production and decay of $\mathrm{ClNO}_{2}$, from the reaction of gaseous $\mathrm{N}_{2} \mathrm{O}_{5}$ with $\mathrm{NaCl}$ solution: Bulk and aerosol experiments, J. Geophys. Res.Atmos., 102, 3795-3804, 1997.

Brunauer, S., Emmett, P. H., and Teller, E.: Adsorption of Gases in Multimolecular Layers, J. Am. Chem. Soc., 60, 309-319, doi:10.1021/ja01269a023, 1938.

Carlier, P., Hannachi, H., and Mouvier, G.: The Chemistry of Carbonyl-Compounds in the Atmosphere - a Review, Atmos. Environ., 20, 2079-2099, 1986.

Carlos-Cuellar, S., Li, P., Christensen, A. P., Krueger, B. J., Burrichter, C., and Grassian, V. H.: Heterogeneous uptake kinetics of volatile organic compounds on oxide surfaces using a Knudsen cell reactor: Adsorption of acetic acid, formaldehyde, and methanol on alpha- $\mathrm{Fe}_{2} \mathrm{O}_{3}$, alpha- $\mathrm{Al}_{2} \mathrm{O}_{3}$, and $\mathrm{SiO}_{2}$, J. Phys. Chem. A, 107, 4250-4261, 2003.

Chiou, C. T. and Shoup, T. D.: Soil Sorption of Organic Vapors and Effects of Humidity on Sorptive Mechanism and Capacity, Environ. Sci. Technol., 19, 1196-1200, 1985.

Dasgupta, P. K., Dong, S., Hwang, H., Yang, H. C., and Genfa, Z.: Continuous Liquid-Phase Fluorometry Coupled to a Diffusion Scrubber for the Real-Time Determination of Atmospheric Formaldehyde, Hydrogen-Peroxide and Sulfur-Dioxide, Atmos. Environ., 22, 949-963, 1988.

DeGomez, T., Kolb, P., and Kleinman, S.: Basic Soil Components, available at: http://articles.extension.org/pages/54401/ basic-soil-components (accessed 10 July 2016), 2015.
DiGangi, J. P., Boyle, E. S., Karl, T., Harley, P., Turnipseed, A., Kim, S., Cantrell, C., Maudlin III, R. L., Zheng, W., Flocke, F., Hall, S. R., Ullmann, K., Nakashima, Y., Paul, J. B., Wolfe, G. M., Desai, A. R., Kajii, Y., Guenther, A., and Keutsch, F. N.: First direct measurements of formaldehyde flux via eddy covariance: implications for missing in-canopy formaldehyde sources, Atmos. Chem. Phys., 11, 10565-10578, doi:10.5194/acp-1110565-2011, 2011.

Donaldson, M. A., Berke, A. E., and Raff, J. D.: Uptake of Gas Phase Nitrous Acid onto Boundary Layer Soil Surfaces, Environ. Sci. Technol., 48, 375-383, 2014a.

Donaldson, M. A., Bish, D. L., and Raff, J. D.: Soil surface acidity plays a determining role in the atmospheric-terrestrial exchange of nitrous acid, P. Natl. Acad. Sci. USA, 111, 18472-18477, doi:10.1073/pnas.1418545112, 2014b.

Fried, A., McKeen, S., Sewell, S., Harder, J., Henry, B., Goldan, P., Kuster, W., Williams, E., Baumann, K., Shetter, R., and Cantrell, C.: Photochemistry of formaldehyde during the 1993 Tropospheric OH Photochemistry Experiment, J. Geophys. Res.Atmos., 102, 6283-6296, 1997.

Fried, A., Crawford, J., Olson, J., Walega, J., Potter, W., Wert, B., Jordan, C., Anderson, B., Shetter, R., Lefer, B., Blake, D., Blake, N., Meinardi, S., Heikes, B., O’Sullivan, D., Snow, J., Fuelberg, H., Kiley, C. M., Sandholm, S., Tan, D., Sachse, G., Singh, H., Faloona, I., Harward, C. N., and Carmichael, G. R.: Airborne tunable diode laser measurements of formaldehyde during TRACEP: Distributions and box model comparisons, J. Geophys. Res.Atmos., 108, 8798, doi:10.1029/2003JD003451, 2003.

Goss, K. U.: Effects of Temperature and Relative-Humidity on the Sorption of Organic Vapors on Quartz Sand, Environ. Sci. Technol., 26, 2287-2294, 1992.

Goss, K. U.: Effects of Temperature and Relative-Humidity on the Sorption of Organic Vapors on Clay-Minerals, Environ. Sci. Technol., 27, 2127-2132, 1993.

Goss, K. U., Buschmann, J., and Schwarzenbach, R. P.: Adsorption of organic vapors to air-dry soils: Model predictions and experimental validation, Environ. Sci. Technol., 38, 3667-3673, 2004.

Gray, C. M., Monson, R. K., and Fierer, N.: Biotic and abiotic controls on biogenic volatile organic compound fluxes from a subalpine forest floor, J. Geophys. Res.-Biogeo., 119, 547-556, 2014.

Hak, C., Pundt, I., Trick, S., Kern, C., Platt, U., Dommen, J., Ordóñez, C., Prévôt, A. S. H., Junkermann, W., Astorga-Lloréns, C., Larsen, B. R., Mellqvist, J., Strandberg, A., Yu, Y., Galle, B., Kleffmann, J., Lörzer, J. C., Braathen, G. O., and Volkamer, R.: Intercomparison of four different in-situ techniques for ambient formaldehyde measurements in urban air, Atmos. Chem. Phys., 5, 2881-2900, doi:10.5194/acp-5-2881-2005, 2005.

Heikes, B., Lee, M. H., Jacob, D., Talbot, R., Bradshaw, J., Singh, H., Blake, D., Anderson, B., Fuelberg, H., and Thompson, A. M.: Ozone, hydroperoxides, oxides of nitrogen, and hydrocarbon budgets in the marine boundary layer over the South Atlantic, J. Geophys. Res.-Atmos., 101, 24221-24234, 1996.

Jacob, D. J.: Heterogeneous chemistry and tropospheric ozone, Atmos. Environ., 34, 2131-2159, 2000.

Jacob, D. J., Heikes, B. G., Fan, S. M., Logan, J. A., Mauzerall, D. L., Bradshaw, J. D., Singh, H. B., Gregory, G. L., Talbot, R. W., Blake, D. R., and Sachse, G. W.: Origin of ozone and $\mathrm{NO}_{x}$ in the tropical troposphere: A photochemical analysis of aircraft obser- 
vations over the South Atlantic basin, J. Geophys. Res.-Atmos., 101, 24235-24250, 1996.

Jaegle, L., Jacob, D. J., Brune, W. H., Faloona, I., Tan, D., Heikes, B. G., Kondo, Y., Sachse, G. W., Anderson, B., Gregory, G. L., Singh, H. B., Pueschel, R., Ferry, G., Blake, D. R., and Shetter, R. E.: Photochemistry of $\mathrm{HO}_{x}$ in the upper troposphere at northern midlatitudes, J. Geophys. Res.-Atmos., 105, 3877-3892, 2000.

Junkermann, W. and Burger, J. M.: A new portable instrument for continuous measurement of formaldehyde in ambient air, J. Atmos. Ocean. Tech., 23, 38-45, 2006.

Kahle, M., Kleber, M., and Jahn, R.: Carbon storage in loess derived surface soils from Central Germany: Influence of mineral phase variables, J. Plant Nutr. Soil Sc., 165, 141-149, 2002.

Kaiser, J., Li, X., Tillmann, R., Acir, I., Holland, F., Rohrer, F., Wegener, R., and Keutsch, F. N.: Intercomparison of Hantzsch and fiber-laser-induced-fluorescence formaldehyde measurements, Atmos. Meas. Tech., 7, 1571-1580, doi:10.5194/amt-7-15712014, 2014.

Kalberer, M., Ammann, M., Arens, F., Gaggeler, H. W., and Baltensperger, U.: Heterogeneous formation of nitrous acid (HONO) on soot aerosol particles, J. Geophys. Res.-Atmos., 104, 1382513832, 1999.

Kebede, M. A., Varner, M. E., Scharko, N. K., Gerber, R. B., and Raff, J. D.: Photooxidation of Ammonia on $\mathrm{TiO}_{2}$ as a Source of $\mathrm{NO}$ and $\mathrm{NO}_{2}$ under Atmospheric Conditions, J. Am. Chem. Soc., 135, 8606-8615, 2013.

Knopf, D. A., Pöschl, U., and Shiraiwa, M.: Radial Diffusion and Penetration of Gas Molecules and Aerosol Particles through Laminar Flow Reactors, Denuders, and Sampling Tubes, Anal. Chem., 87, 3746-3754, 2015.

Kormann, R., Fischer, H., de Reus, M., Lawrence, M., Brühl, Ch., von Kuhlmann, R., Holzinger, R., Williams, J., Lelieveld, J., Warneke, C., de Gouw, J., Heland, J., Ziereis, H., and Schlager, H.: Formaldehyde over the eastern Mediterranean during MINOS: Comparison of airborne in-situ measurements with 3D-model results, Atmos. Chem. Phys., 3, 851-861, doi:10.5194/acp-3-851-2003, 2003.

Kulmala, M. and Petaja, T.: Soil Nitrites Influence Atmospheric Chemistry, Science, 333, 1586-1587, 2011.

Lammel, G.: Formation of Nitrous Acid: Parameterisation and Comparison with Observations, Max-Planck-Institut für Meteorologie, Publisher location: Hamburg, Germany, 286, 1999.

Lee, Y. N., Zhou, X., Kleinman, L. I., Nunnermacker, L. J., Springston, S. R., Daum, P. H., Newman, L., Keigley, W. G., Holdren, M. W., Spicer, C. W., Young, V., Fu, B., Parrish, D. D., Holloway, J., Williams, J., Roberts, J. M., Ryerson, T. B., and Fehsenfeld, F. C.: Atmospheric chemistry and distribution of formaldehyde and several multioxygenated carbonyl compounds during the 1995 Nashville Middle Tennessee Ozone Study, J. Geophys. Res.-Atmos., 103, 22449-22462, 1998.

Li, X., Rohrer, F., Brauers, T., Hofzumahaus, A., Lu, K., Shao, M., Zhang, Y. H., and Wahner, A.: Modeling of HCHO and CHO$\mathrm{CHO}$ at a semi-rural site in southern China during the PRIDEPRD2006 campaign, Atmos. Chem. Phys., 14, 12291-12305, doi:10.5194/acp-14-12291-2014, 2014.

Liu, S. C., Trainer, M., Carroll, M. A., Hubler, G., Montzka, D. D., Norton, R. B., Ridley, B. A., Walega, J. G., Atlas, E. L., Heikes, B. G., Huebert, B. J., and Warren, W.: A Study of the Photochemistry and Ozone Budget during the Mauna-Loa-Observatory Pho- tochemistry Experiment, J. Geophys. Res.-Atmos., 97, 1046310471, 1992.

Lowe, D. C. and Schmidt, U.: Formaldehyde (HCHO) measurements in the nonurban atmosphere, J. Geophys. Res., 88, 1084410858, 1983.

Monge, M. E., D’Anna, B., Mazri, L., Giroir-Fendler, A., Ammann, M., Donaldson, D. J., and George, C.: Light changes the atmospheric reactivity of soot, P. Natl. Acad. Sci. USA, 107, 66056609, 2010.

Morrissey, F. A. and Grismer, M. E.: Kinetics of volatile organic compound sorption/desorption on clay minerals, J. Contam. Hydrol., 36, 291-312, 1999.

Murphy, D. M. and Fahey, D. W.: Mathematical Treatment of the Wall Loss of a Trace Species in Denuder and Catalytic-Converter Tubes, Anal. Chem., 59, 2753-2759, 1987.

Ong, S. K. and Lion, L. W.: Mechanisms for Trichloroethylene Vapor Sorption onto Soil Minerals, J. Environ. Qual., 20, 180-188, 1991a.

Ong, S. K. and Lion, L. W.: Effects of Soil Properties and Moisture on the Sorption of Trichloroethylene Vapor, Water Res., 25, 2936, $1991 b$.

Oswald, R., Behrendt, T., Ermel, M., Wu, D., Su, H., Cheng, Y., Breuninger, C., Moravek, A., Mougin, E., Delon, C., Loubet, B., Pommerening-Roser, A., Sorgel, M., Poschl, U., Hoffmann, T., Andreae, M. O., Meixner, F. X., and Trebs, I.: HONO Emissions from Soil Bacteria as a Major Source of Atmospheric Reactive Nitrogen, Science, 341, 1233-1235, 2013.

Parrish, D. D., Ryerson, T. B., Mellqvist, J., Johansson, J., Fried, A., Richter, D., Walega, J. G., Washenfelder, R. A., de Gouw, J. A., Peischl, J., Aikin, K. C., McKeen, S. A., Frost, G. J., Fehsenfeld, F. C., and Herndon, S. C.: Primary and secondary sources of formaldehyde in urban atmospheres: Houston Texas region, Atmos. Chem. Phys., 12, 3273-3288, doi:10.5194/acp-12-32732012, 2012.

Pei, J. J. and Zhang, J. S. S.: On the performance and mechanisms of formaldehyde removal by chemi-sorbents, Chem. Eng. J., 167, 59-66, 2011.

Pennell, K. D., Rhue, R. D., Rao, P. S. C., and Johnston, C. T.: Vapor-Phase Sorption of Para-Xylene and Water on Soils and Clay-Minerals, Environ. Sci. Technol., 26, 756-763, 1992.

Preunkert, S., Legrand, M., Pepy, G., Gallee, H., Jones, A., and Jourdain, B.: The atmospheric HCHO budget at Dumont d'Urville (East Antarctica): Contribution of photochemical gasphase production versus snow emissions, J Geophys. Res.Atmos., 118, 13319-13337, 2013.

Preunkert, S., Legrand, M., Frey, M. M., Kukui, A., Savarino, J., Gallée, H., King, M., Jourdain, B., Vicars, W., and Helmig, D.: Formaldehyde (HCHO) in air, snow, and interstitial air at Concordia (East Antarctic Plateau) in summer, Atmos. Chem. Phys., 15, 6689-6705, doi:10.5194/acp-15-6689-2015, 2015.

Price, H., Jaegle, L., Rice, A., Quay, P., Novelli, P. C., and Gammon, R.: Global budget of molecular hydrogen and its deuterium content: Constraints from ground station, cruise, and aircraft observations, J. Geophys. Res.-Atmos., 112, D22108, doi:10.1029/2006JD008152, 2007.

Punrattanasin, P. and Sariem, P.: Adsorption of Copper, Zinc, and Nickel Using Loess as Adsorbents, Pol. J. Environ. Stud., 24, 1259-1266, doi:10.15244/pjoes/30264, 2015. 
Rodier, D. R. and Birks, J. W.: Evaluation of Isoprene Oxidation as an Interference in the Cartridge Sampling and Derivatization of Atmospheric Carbonyl-Compounds, Environ. Sci. Technol., 28, 2211-2215, 1994.

Ruiz, J., Bilbao, R., and Murillo, M. B.: Adsorption of different VOC onto soil minerals from gas phase: Influence of mineral, type of VOC, and air humidity, Environ. Sci. Technol., 32, 10791084, 1998.

Sassine, M., Burel, L., D’Anna, B., and George, C.: Kinetics of the tropospheric formaldehyde loss onto mineral dust and urban surfaces, Atmos. Environ., 44, 5468-5475, 2010.

Seinfeld, J. H. and Pandis, S. N.: Atmospheric Chemistry and Physics: From Air Pollution to Climate Change, 2nd Edn., Wiley, New York, 2006.

Smith, J. A., Chiou, C. T., Kammer, J. A., and Kile, D. E.: Effect of Soil Moisture on the Sorption of Trichloroethene Vapor to Vadose-Zone Soil at Pictinny Arsenal, New Jersey, Environ. Sci. Technol., 24, 676-683, 1990.

Su, H., Cheng, Y. F., Oswald, R., Behrendt, T., Trebs, I., Meixner, F. X., Andreae, M. O., Cheng, P., Zhang, Y., and Pöschl, U.: Soil Nitrite as a Source of Atmospheric HONO and OH Radicals, Science, 333, 1616-1618, 2011.

Tie, X., Brasseur, G., Emmons, L., Horowitz, L., and Kinnison, D.: Effects of aerosols on tropospheric oxidants: A global model study, J. Geophys. Res.-Atmos., 106, 22931-22964, 2001.

Toda, K., Yunoki, S., Yanaga, A., Takeuchi, M., Ohira, S. I., and Dasgupta, P. K.: Formaldehyde Content of Atmospheric Aerosol, Environ. Sci. Technol., 48, 6636-6643, 2014.

Unger, D. R., Lam, T. T., Schaefer, C. E., and Kosson, D. S.: Predicting the effect of moisture on vapor-phase sorption of volatile organic compounds to soils, Environ. Sci. Technol., 30, 10811091, 1996
Usher, C. R., Michel, A. E., and Grassian, V. H.: Reactions on mineral dust, Chem. Rev., 103, 4883-4939, 2003.

VandenBoer, T. C., Young, C. J., Talukdar, R. K., Markovic, M. Z., Brown, S. S., Roberts, J. M., and Murphy, J. G.: Nocturnal loss and daytime source of nitrous acid through reactive uptake and displacement, Nat. Geosci., 8, 55-60, doi:10.1038/ngeo2298, 2015.

Wagner, V., von Glasow, R., Fischer, H., and Crutzen, P. J.: Are $\mathrm{CH}_{2} \mathrm{O}$ measurements in the marine boundary layer suitable for testing the current understanding of $\mathrm{CH}_{4}$ photooxidation?: A model study, J. Geophys. Res.-Atmos., 107, 4029, doi:10.1029/2001JD000722, 2002.

Wang, L., Wang, W. G., and Ge, M. F.: Heterogeneous uptake of $\mathrm{NO}_{2}$ on soils under variable temperature and relative humidity conditions, J. Environ. Sci.-China, 24, 1759-1766, doi:10.1016/S1001-0742(11)61015-2, 2012.

Weller, R., Schrems, O., Boddenberg, A., Gab, S., and Gautrois, M.: Meridional distribution of hydroperoxides and formaldehyde in the marine boundary layer of the Atlantic $\left(48^{\circ} \mathrm{N}-35^{\circ} \mathrm{S}\right)$ measured during the Albatross campaign, J. Geophys. Res.-Atmos., 105, 14401-14412, 2000.

Xu, B. Y., Shang, J., Zhu, T., and Tang, X. Y.: Heterogeneous reaction of formaldehyde on the surface of gamma- $\mathrm{Al}_{2} \mathrm{O}_{3}$ particles, Atmos. Environ., 45, 3569-3575, 2011.

Zhou, X. L., Lee, Y. N., Newman, L., Chen, X. H., and Mopper, K.: Tropospheric formaldehyde concentration at the Mauna Loa observatory during the Mauna Loa observatory photochemistry experiment 2, J. Geophys. Res.-Atmos., 101, 14711-14719, 1996. 